\title{
The use of a three-dimensional elastic model to identify rock mass damaged areas in the undercut level at Reservas Norte sector
}

\author{
D.A. Cuello Codelco Chile, Chile \\ P.P. Landeros Codelco Chile, Chile \\ P.H. Cavieres Codelco Chile, Chile
}

\begin{abstract}
The induced stress originated by caving mining activity in the Reservas Norte sector of El Teniente Mine has caused rock mass damages at the undercut level. This damage could hinder the undercutting process and could affect the normal operation of the mine. Therefore, being able to predict which undercutting sequences may cause damage and identify where the damage could be located may contribute in the decision making process when planning different mining sequences. The use of a three-dimensional elastic model is a powerful tool to identify these areas. For the Reservas Norte sector a three-dimensional elastic model was calibrated using the stress measurement and rock mass damage mapping at the undercut level for three different periods of time. This study shows how the model was calibrated and the criteria used to calibrate the model.
\end{abstract}

\section{Introduction}

\subsection{El Teniente Mine overview}

El Teniente Mine is a Codelco Chile underground copper mine. It is located in the Andes range in the central zone of Chile, about $70 \mathrm{~km}$ SSE from the capital city, Santiago (Figure 1).

El Teniente is the largest known copper-molybdenum deposit in the world. It is hosted in a copper porphyry system. The main rock types include andesite, diorite and hydrothermal breccias of the Miocene era. Since 1906, more than 1,100 million tons of ore have been mined. The mine is currently extracting around 140,000 tons/day using mechanised caving methods. Panel and post-undercut caving methods, variations of the standard block caving, were introduced in 1982 and 1994, respectively to exploit primary copper ore.

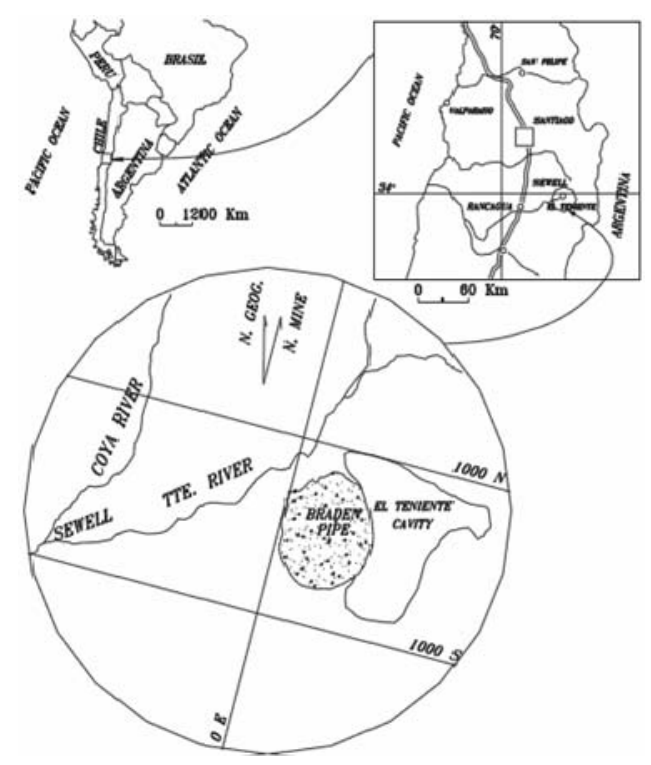

Figure 1 Location of EI Teniente Mine (Rojas et al., 2001) 


\subsection{Reservas Norte sector overview}

El Teniente Mine includes different production sectors (Figure 2), all of them located around a chimney of sub-volcanic breccias with an inverted cone shape, known as 'Braden Pipe'. Reservas Norte - also called as Sub6 sector at the beginning - is located on the north-eastern side and started its exploitation in 1989 using a conventional panel caving. Several rockbursts occurred during the 1990s and different exploitation sequences were tested to ensure its continuity.

Up to now, Reservas Norte is mined by advance panel caving, considering a production plan close to 30,000 tons/day.

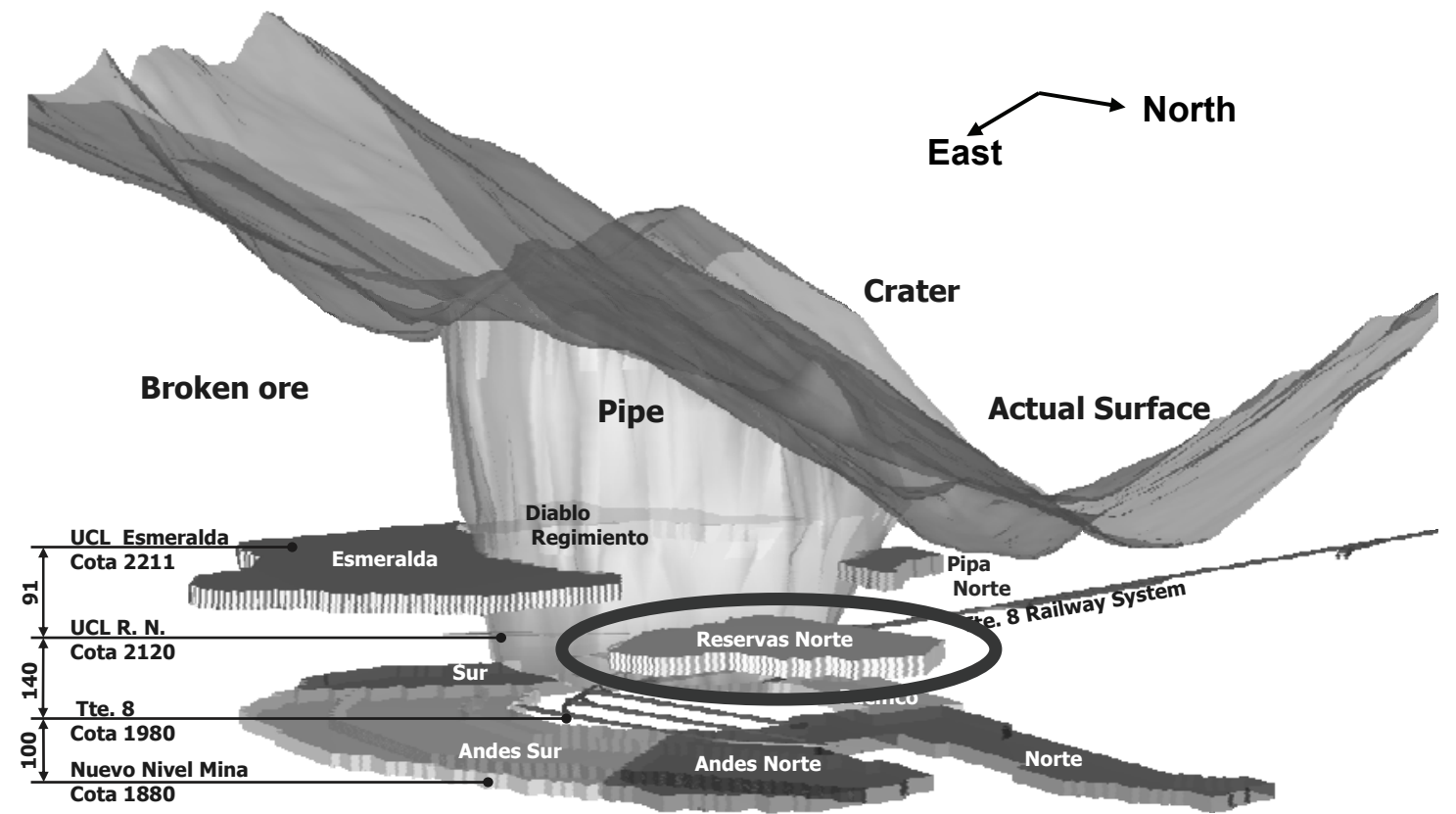

Figure 2 Productive sectors and projects, El Teniente Mine

\subsection{Geological and geotechnical data}

Predominant lithology corresponds to Andesite intruded by three major ore bodies: dacite porphyry and anhydrite breccia on the western side; diorite porphyry, on the central and eastern side. Intact rock properties and rock mass quality indexes are detailed in Table 1.

Most important geological faults are classified as Master Faults (faults G, C, N1 and N2) and Major Faults (faults F, AND-1, AND-2, AND-3, AND-4 and AND-5). In Figure 3, a geological plan view is shown.

Table 1 Intact rock properties and rock mass quality indexes (Brzovic, 2000)

\begin{tabular}{|c|c|c|c|c|c|}
\hline & & & & \\
\hline & & Andesite & Dacite Porphyry & Diorite Porphyry & Anhydrite Breccia \\
\hline Intact & $\mathrm{E}(\mathrm{GPa})$ & 60 & 30 & 45 & 41 \\
\hline \multirow[t]{5}{*}{ Rock } & $v$ & 0.16 & 0.18 & 0.21 & 0.20 \\
\hline & $\gamma(\mathrm{t} / \mathrm{m} 3)$ & 2.8 & 2.6 & 2.7 & 2.7 \\
\hline & UCS (MPa) & 120 & 110 & 140 & 102 \\
\hline & Coh (MPa) & 23 & 19 & 23 & 19 \\
\hline & $\Phi\left(^{\circ}\right)$ & 38 & 48 & 38 & 39 \\
\hline Rock & IRMR & $55-60$ & $58-63$ & $59-62$ & $58-62$ \\
\hline Mass & GSI & $70-90$ & $75-90$ & $70-90$ & $80-90$ \\
\hline
\end{tabular}




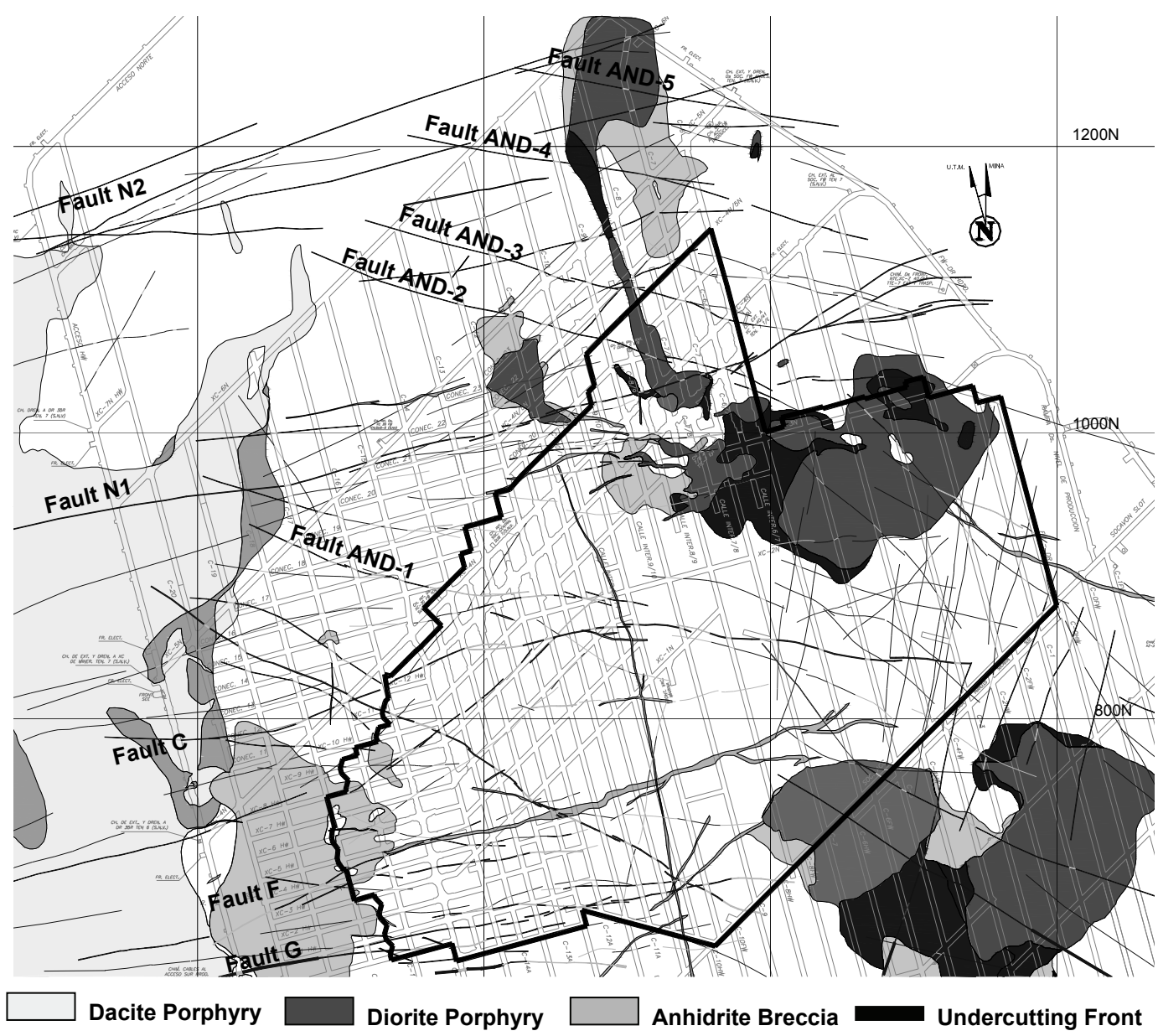

Figure 3 Plan view of geology in Reservas Norte sector, undercutting level (Benado, 2009)

\subsection{Pre-mining stress state}

Table 2 Pre-mining stress state at Reservas Norte sector

\begin{tabular}{lccc}
\hline Principal Stresses & Magnitude $(\mathbf{M P a})$ & Azimuth $\left({ }^{\circ}\right)$ & Plunge $\left({ }^{\circ}\right)$ \\
\hline Major principal stress $\left(\sigma_{1}\right)$ & $45 \pm 5$ & 138 & -14 \\
Intermediate principal stress $\left(\sigma_{2}\right)$ & $38 \pm 4$ & 231 & -12 \\
Minor principal stress $\left(\sigma_{3}\right)$ & $28 \pm 4$ & 2 & -71 \\
\hline
\end{tabular}

\section{$2 \quad$ Damage mapping}

One of the most relevant characteristics of Panel Caving method is related to its dynamism, which constantly modifies the state of stress, inducing damage in galleries close to the advancing front.

To evaluate this damage, a methodology was created many years ago at El Teniente Mine, in order to identify and quantify principal variables related to these changes, mainly: over break, block conditions, reinforcement conditions and water infilling. Each parameter is ranked and finally the four parameters are three different levels of damage (low, regular and severe damage). For this study only severe damage is considered, an example of severe damage in the undercut level is shown in Figure 4. 


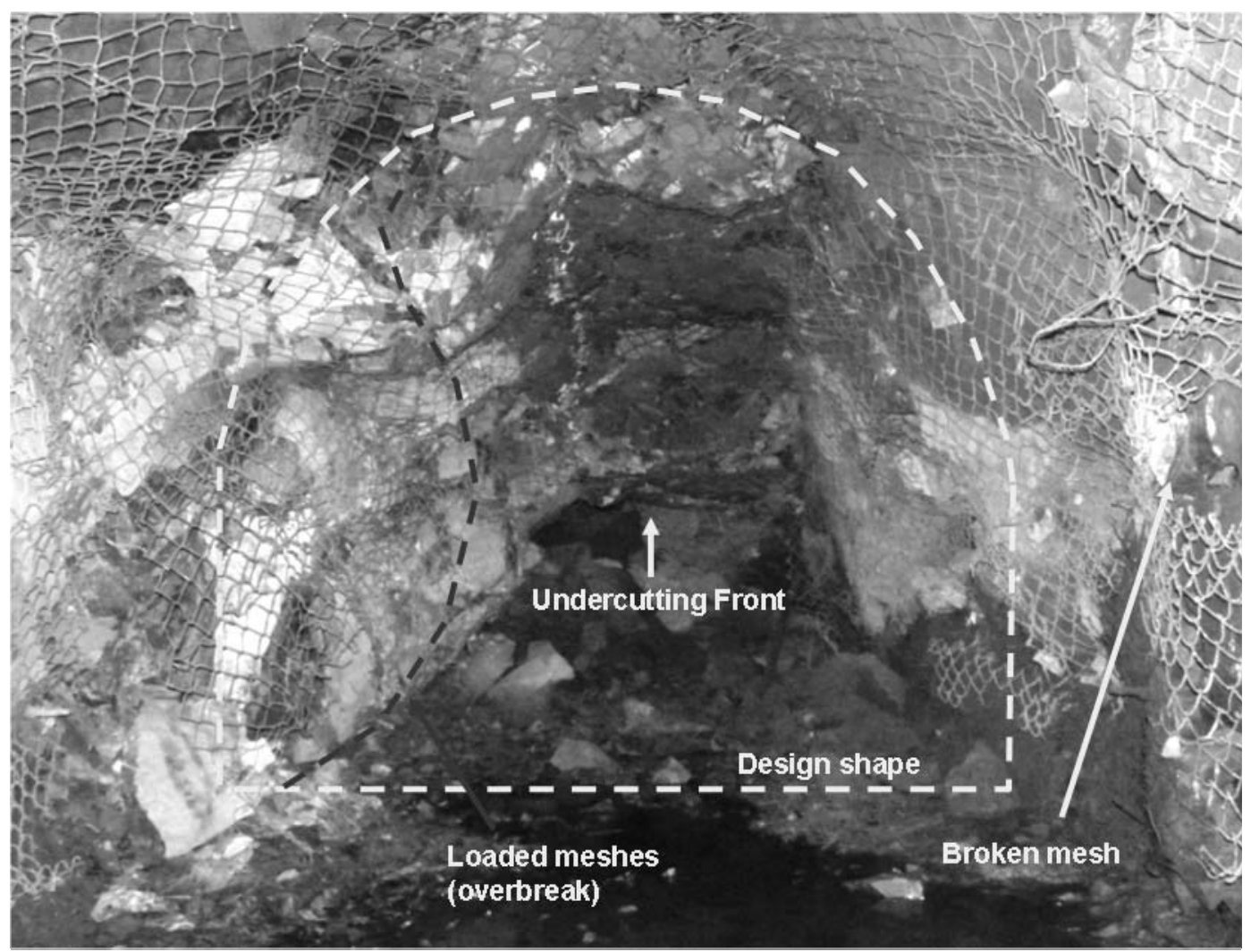

Figure 4 Example of severe damage in the undercut level, Reservas Norte sector

\section{$3 \quad$ Numerical modelling}

\subsection{Numerical analysis overview}

A Map3D (linear elastic boundary element code) was used to model the geometries involved in this project. Boundary element codes are efficient at modelling large areas and model building is simplified as only the mining geometry boundaries need to be discretised. Models were built for years 2005, 2007 and 2009 and they consider the effect of topography and main lithologies. As an elastic model was used as well as the geometry only few parameters needed specification.

\subsection{The 3D numerical modelling implementation for stress analysis at Reservas Norte sector}

The philosophy behind numerical modelling adopted for the Rock mechanic engineering group at El Teniente Mine is to create evidence based calibrated models. Here, the objective is to create a model providing the best match with observe behaviour and recorded data. Once, the numerical model shows a satisfactory agreement with observed and recorded data, then the model can be used as a geotechnical planning tool, as shown in Figure 5.

Until 2006, 3D numerical modelling at El Teniente Mine had been developed and used in detailed analysis cases, basically because of the time and resources involved in building and running models. With the implementation of Map3D, less time was required to develop 3D analysis; rock mechanic engineers where provided with a comparative tool to either complement their support planning or project decisions.

Specifically related to Reservas Norte sector, the first 3D model (using Map3D) was build in 2007, including all cavities around Reservas Norte, this model was used to complement the evaluation of different proposed mining alternatives in the medium and long term horizon.

One year later (Pardo and Landeros, 2008), the model geometry was updated and some calibrations for Pilar Norte and Diablo Regimiento's analysis were adapted using the Reservas Norte's information. Once again, 
3D numerical modelling was used to compare mining sequence alternatives for new mining areas, at this time a local criterion from damage ahead of the undercutting was introduced, including explicit galleries. Further analyses searched for continuous improvements (Cuello et al., 2010), considering explicit galleries and improving calibrations in terms of stresses, damage and a new source of calibration, such as information from preconditioning by hydro-fracturing.

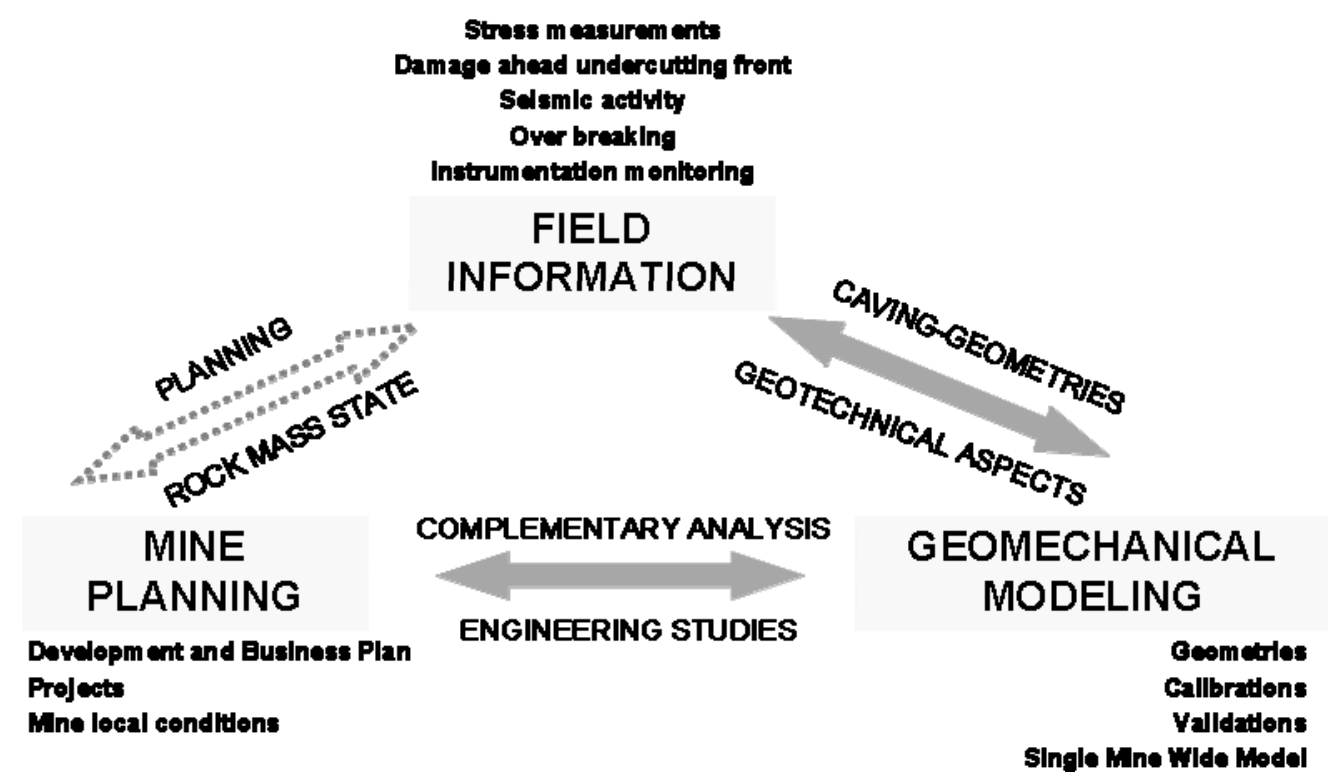

Figure 5 Numerical modelling strategy (Pardo and Landeros, 2008)

\subsection{Numerical analysis overview}

A Map3D (linear elastic boundary element code) was used to model the geometries involved in this project. Boundary element codes are efficient at modelling large areas and model building is simplified as only the mining geometry boundaries need to be discretised. Models were built for years 2005, 2007 and 2009 and consider the effect of topography and main lithologies. As an elastic model was used besides the geometry only few parameters needed to be specified.

\subsection{Geometry}

The Map3D Model constructed for this analysis encompassed three different materials; they were Andesites which is the most prominent body in the mine, Braden Pipe which is surrounded by all exploitation sectors of the mine and finally, the broken material inside the cavity left by the caving process (see Figure 6).

Major faults were not included in the model as most of the damage in the undercut has been caused by overstress on the rock mass rather than slip along existing faults. Development drives for undercut were only include at the Reservas Norte sector as the effect of drives in other sectors on the stability at the Reservas Norte can be neglected. There are two options to achieve geometries:

- Through in the geometry and let the program builds the intersections and overlaps. This option is easy to build, but the program will take a long time to run and some difficulties with complex shapes may appear.

- Build the geometry, in such a way that each part joins the next seamlessly. This option takes more time to build the model but it will run much more quickly.

For this analysis, the adopted option corresponds to build clean models (see Figure 6). Geometries included in the model are: all cave sectors, including exhausted and current operation; whole mine topography, including subsidence; extraction zone, undercutting and undercut drives only for Reservas Norte and finally Braden Pipe. 


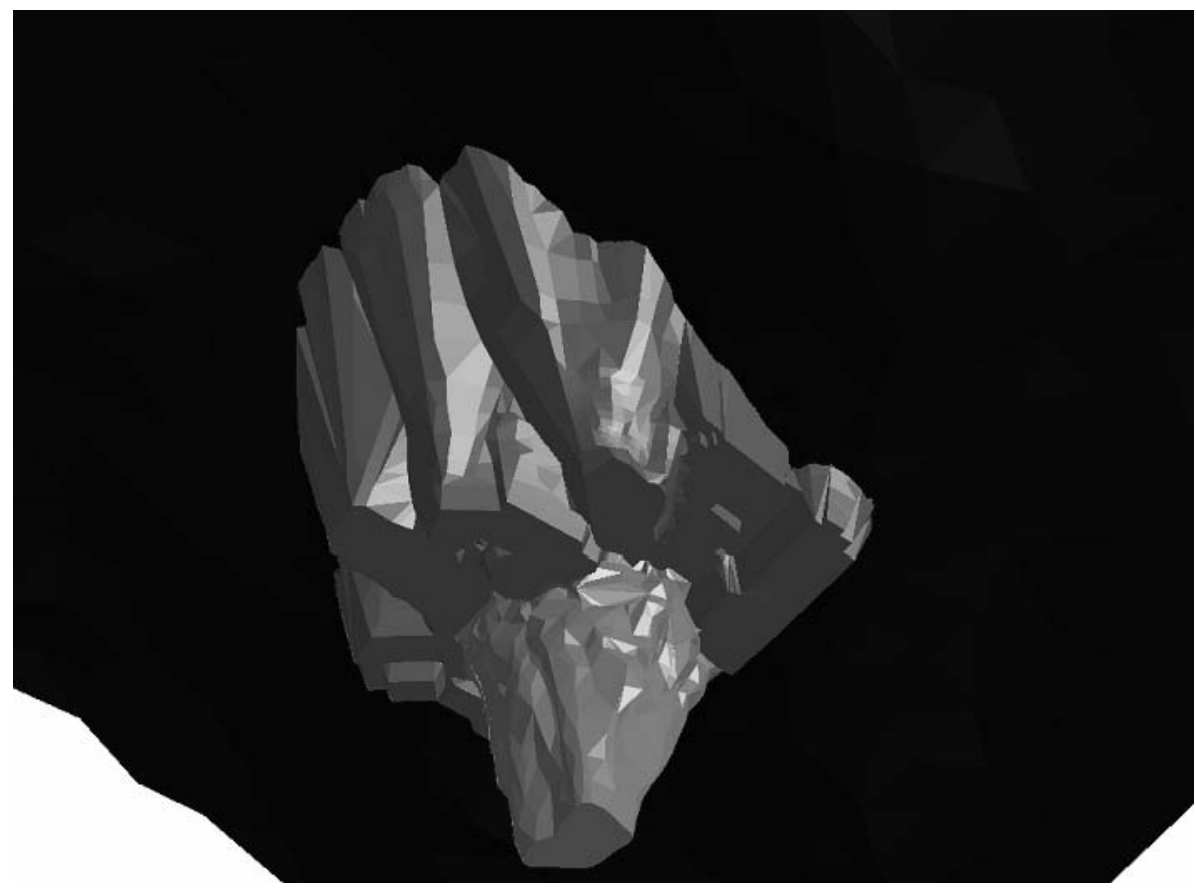

Figure 6 Geometries built mine wide scale

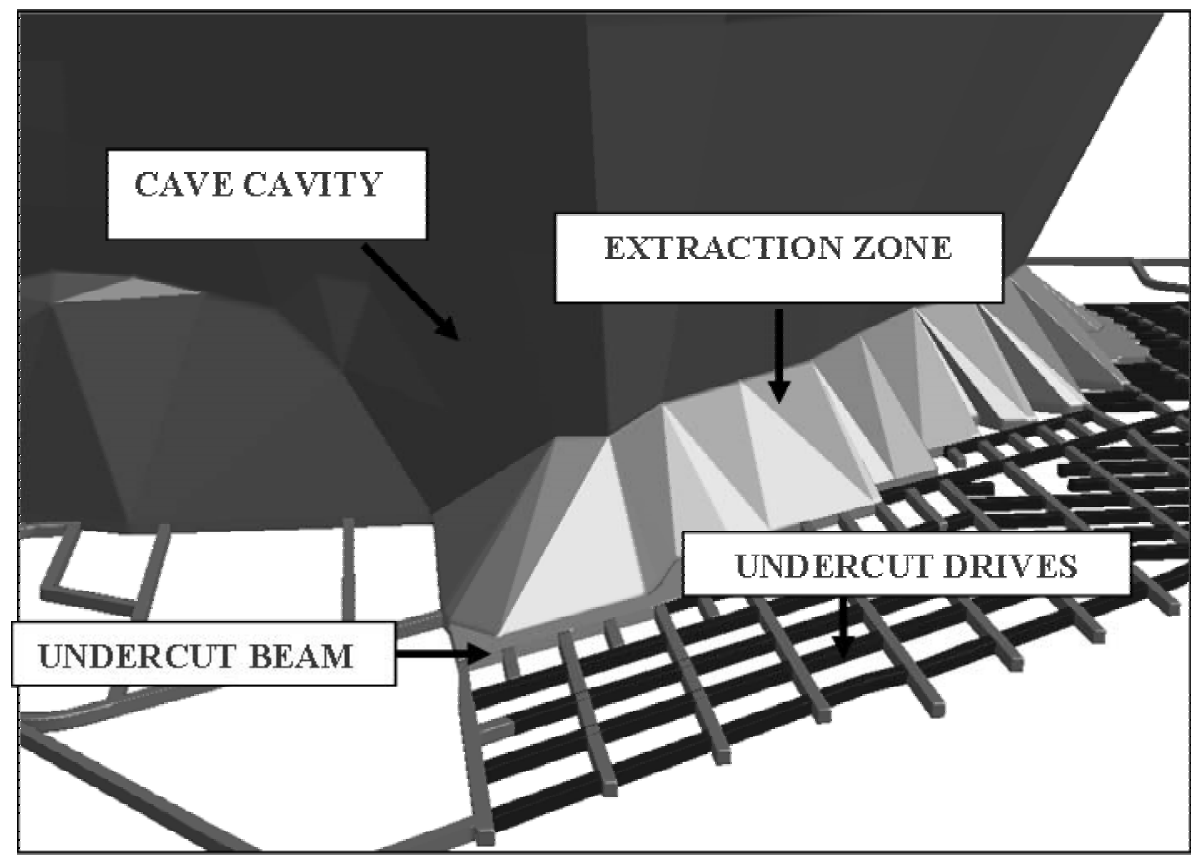

Figure 7 Details included in the study area

\subsection{Loading conditions}

The stress state of a material in Map3D is specified as a linear variation with depth in either principal or cartesian components. When using principal components, one has to specify three directions to determine the orientation of the principal stresses as well as the combination of three magnitude constants and three magnitude gradients to determine the linear variation of principle stress magnitude with depth - nine constants in total.

The orientation was set to the average orientation of the measurements at Reservas Norte and by choosing the stress datum at an elevation of 3,680 $\mathrm{m}$ above ground level, the magnitude constants could be set to 0 . For the remaining three constants, the magnitude gradients, were then obtained from the stress measurement 
data using a simplex/hill climber minimisation method on the mis-fit function between modelled and observed stresses. Input stress parameters for the Map3D model are summarised in Table 3.

Table 3 Stress input parameters for each material considered

\begin{tabular}{llll}
\hline Input Parameter & Andesite & Braden Breccia & Cave Material \\
\hline Datum & 3,680 & 2,160 & 3,300 \\
$\sigma_{1}(\mathrm{MPa})$ & 0 & -37 & 0 \\
$\sigma_{2}(\mathrm{MPa})$ & 0 & -23 & 0 \\
$\sigma_{3}(\mathrm{MPa})$ & 0 & -20 & 0 \\
$\Delta \sigma_{1}$ & 0.038 & -0.042 & 0.020 \\
$\Delta \sigma_{2}$ & 0.026 & -0.036 & 0.006 \\
$\Delta \sigma_{3}$ & 0.025 & -0.032 & 0.006 \\
$\sigma_{1}$ trend $\left(^{\circ}\right)$ & 90 & 340 & 0 \\
$\sigma_{2}$ trend $\left(^{\circ}\right)$ & 30 & 5 & 90 \\
$\sigma_{3}$ trend $\left(^{\circ}\right)$ & 180 & 90 & 0 \\
\hline
\end{tabular}

\subsection{Cave material}

In boundary element numerical models, there are two ways in which broken material within the cave can be simulated. The first method simply specifies a different material for the solid surrounding rock and the broken rock within the cave. When this approach is taken, the usual stress and displacement continuity conditions must be satisfied on the interface between these two materials. Nevertheless, using this approach the model was found to be unstable, due to the extremely low elastic modulus used for the broken material. The second method for modelling broken rock within the cave uses the normal solid rock properties outside the cave, and specifies appropriate traction conditions on the surface of the cave. While not as realistic as the multiple material approaches, this is at least numerically stable and was consequently used in this analysis.

To estimate these traction conditions, a density of $2,000 \mathrm{~kg} / \mathrm{m}^{3}$ was assumed for the broken material. The vertical component of the traction at any point on the cave wall will vary linearly with depth with the gravitational acceleration constant. The horizontal components of the traction were then related to the vertical component by a ratio $\mathrm{S}_{\mathrm{h}} / \mathrm{S}_{\mathrm{v}}=\mathrm{k}$.

Tests were performed with $\mathrm{k}$ ratios of $1.00,0.75,0.5,0.25$ and 0.00 as well as assuming air in the cave to see which model agrees best with the stress measurement data. It was found that the $\mathrm{k}$ assumption did not have a large impact when compared with the actual stress measurements.

Finally, the cave zone was simulated using gravity loading with a ratio $\mathrm{S}_{\mathrm{h}} / \mathrm{S}_{\mathrm{v}}=0.3$. This value was chosen by applying ranking active state assuming zero cohesion and a friction angle equal to $30^{\circ}$. As the cave wall is failing, loosening and material is breaking off, it can be assumed that confinement acting on the cave walls must be low enough so that the strength is at least equal to the stresses.

\subsection{Modelling strategy}

The modelling strategy for this study considers two stages: First, find the pre-processing parameters such as initial stress condition for the model which best match stress measurement at Reservas Norte mine. Second, find the best post-processing parameters to correlate severe damage observed at the undercut level.

The objective of evidence based calibrated modelling is to create a model that provides a best possible match to observed behaviour. Hence that model is calibrated to provide the best approach to actual observations, in this study, damage on drives at the undercut level. Alternatives are compared on an objective basis through attempts to minimise the error between the model prediction and the observations. 
The model built for this analysis is based on the large scale model. As this large model was planned to give an initial idea about stress conditions at different sectors of the mine, it was found that when this model is applied to specific areas to predict damage, the model needs to be adjusted to meet the local area of interest conditions. The local conditions are highly influenced by the smaller geometries such as: drawells, drives and cave back assumptions.

Since models only predict stress, strain and displacement, it is necessary to be specific about how to compare model predictions with observations, hence that in this study the likelihood of rock mass damage was calculated, considering predicted stress states from the model above the best fit strength envelope.

\section{$4 \quad$ Rock mass damage prediction}

\subsection{Rock mass damage}

One of the fundamental problems in continuum analysis of large structures in rock such as cave mining is the estimation of rock mass strength. Due to the nearly impossible task of measuring rock mass strength directly, it usually estimated from empirical relations based on rock-mass classification systems. At the Reservas Norte sector, when this approach was taken it did not show good correlation with observations. Consequently, an alternative methodology to predict damage was followed; this methodology for correlating model predictions and observed rock response can be done objectively by defining a standard error, considering the following:

- By calculating the difference between the predicted stress level and the best fit strength envelope meant to represent this.

- By calculating the difference between the predicted and observed damage locations by using different set of rock mass strength properties.

Damage calibration requires that model prediction correlate with observed response on several issues:

- Damage should be predicted in the model at the same location and extent as observed in the mine. Conversely, damage should be predicted to not occur in the model at the same location as it is observed not to occur in the mine.

- Damage predicted in the model should be at the same point in the mining sequence and not at other times.

- Damage magnitude should agree with observations. While optimally one would like agreement with measured values, the minimum relative magnitudes must coincide.

- The direction of movement indicated by the model and that observed must coincide.

Finally, these comparisons must be made at various different locations with different geometries and shapes. This last requirement ensures any derived criteria is more universally applicable and not dependant on some local assumption.

\subsection{Adopted methodology for predicting damage}

Wiles (1999) suggested that rock mass damage can be related to linear elastic overstress, this criteria can be seen in Figure 8. Although this criteria has some limitation when applied in areas where loss of confinement (relaxation) cause the change in the loading conditions that trigger the failure, it works properly when damage to the rock mass is caused by increments of major principal stress.

The undercut level at Reservas Norte sector considers different dimensions for drives, the pillar dimensions vary depending on the layout across the undercut level. Instability of the undercut levels have shown evidence to be caused by induced stresses built up in the boundaries of the undercut front. Base on this, it can be said that overstress criteria can be use to predict damage at the undercut level. 


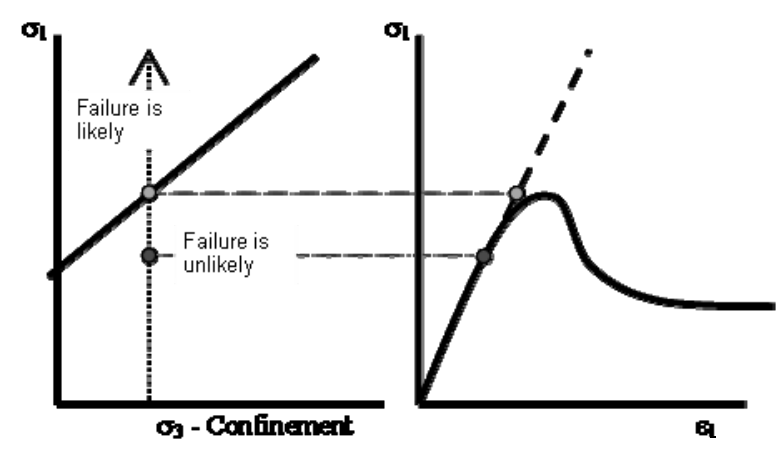

Figure 8 Relationship between elastic models and damage (Wiles, 1999)

\subsection{Stress state definition}

\subsubsection{Host material}

To validate the numerical model, the modelled stress state was tested against 13 conventional stress measurements which correspond to the 2009 geometry. The stresses calculated by the model were then compared to each available stress measurement and finally the error for the stress tensor was calculated using the following equation:

$$
\varepsilon=\frac{\sqrt{\Sigma\left(\sigma_{m}-\sigma_{f}\right)^{2}}}{\sqrt{\Sigma\left(\sigma_{m}\right)^{2}}}
$$

Where $\sigma_{\mathrm{m}}$ is the stress tensor measured at the field and $\sigma_{\mathrm{f}}$ is the stress tensor calculated by the model.

Several pre-mining stress orientations were tested until the in situ stress condition reducing the error to minimal value was found. The range for the stress orientation was defined based on the stress measurement variation. Considering that principal stress must be orthogonal it is only necessary to vary trend and plunge of one of the principal stresses and only the trend for the minor principal stress. In this analysis, the trend and plunge for $\sigma_{1}$ was varied from 10 to $50^{\circ}$, and 50 to $170^{\circ}$ respectively.

It was found that averaging the error given by the comparison of each modelled and measured stresses could lead to choose the wrong input parameters. Hence, that for this study, the error of each modelled stress tensor was weighted by the inverse of the distance from the stress measurement position and the area of interest. Finally, the minimum error, which corresponds to a $32 \%$, between the modelled and measured stress could be found when using trend and plunge for S1 equal to 90 and $30^{\circ}$ respectively, as can be seen in Figure 9 .

\section{Trend \& Plunge Variation}

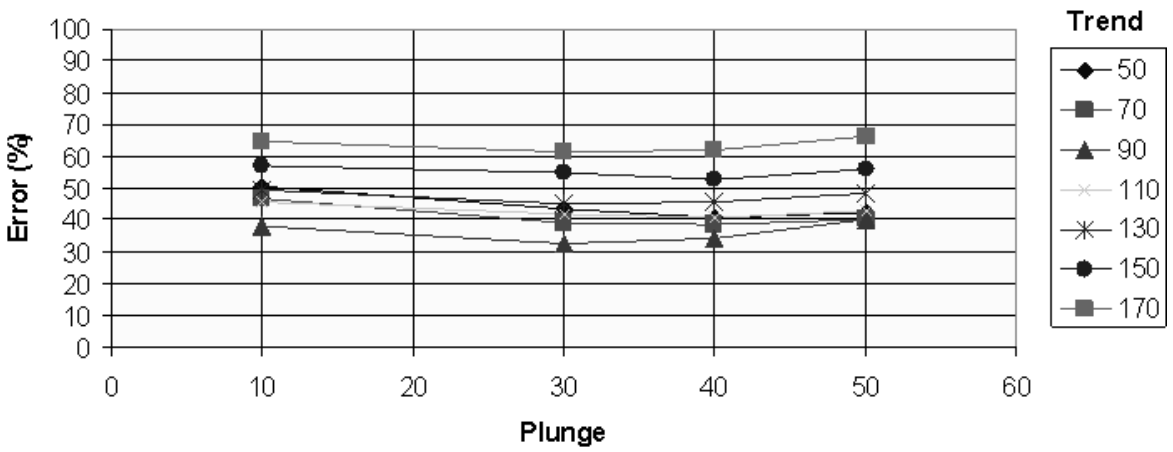

Figure 9 Error variations for different stress inputs in the model 


\subsubsection{Cave material}

Reopening pressures from Hydro-fractures were found to be valuable information to be used in order to validate the stress assumption made for the cave material at Reservas Norte numerical model. Information recorded for reopening pressure for hydro-fracturing holes were compared with the model prediction by entering the coordinates at the location where fractures were generated into the Map3D model, see Figure 10. Several cave stress assumptions were tested against recorded hydro-fracture reopening pressures until obtaining the best correlation between the recorded data and the model prediction as shown in Figure 11 . Finally, it was found that the best correlation occurs when cave zone was simulated using gravity loading with a ratio $\mathrm{S}_{\mathrm{h}} / \mathrm{S}_{\mathrm{v}}=0.3$.

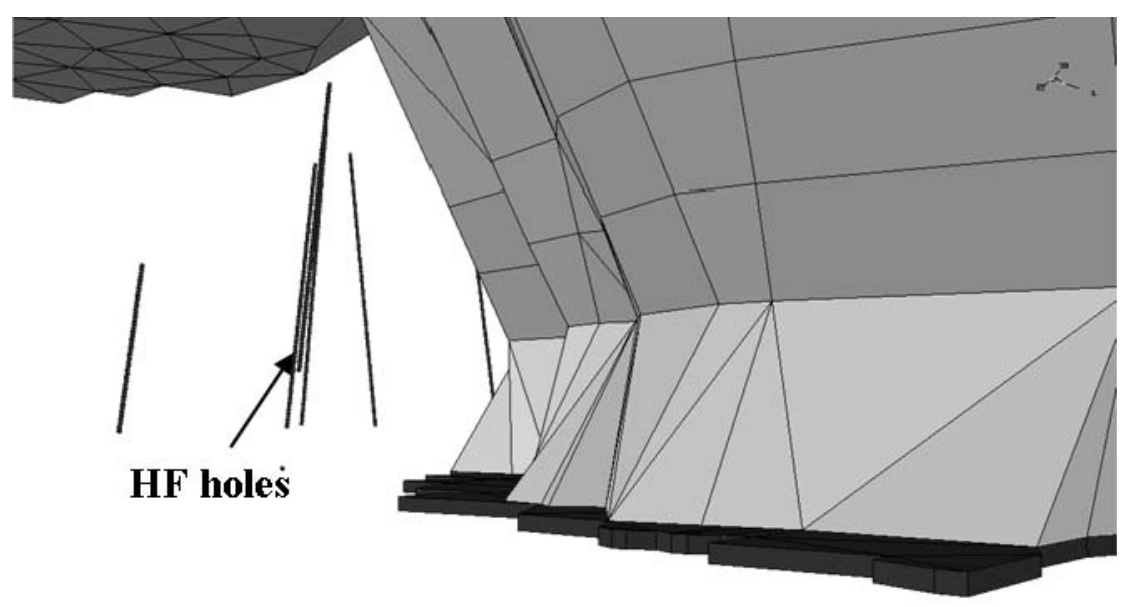

Figure 10 Location for Hydro-fracturing holes used in Map3D
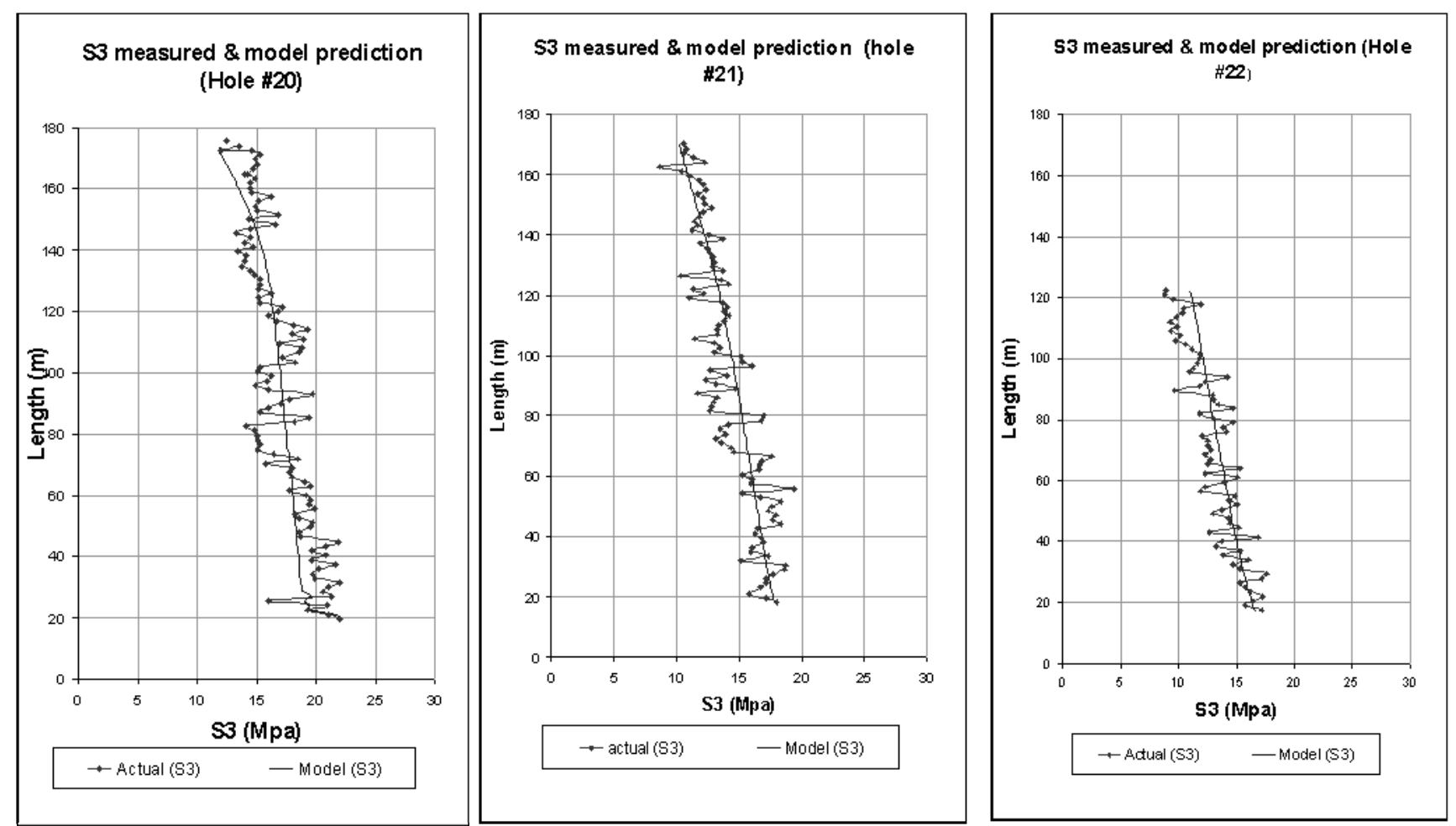

Figure 11 Comparison between actual and modelled principal minor stress 


\subsection{Parametric study}

Once the model results indicated a satisfactory degree of calibration against stress measurement, the model was used to investigate the impact of model assumptions on the damage prediction. All parameters investigated showed a minor effect for stress calibration process.

\subsubsection{Stress state datum for cave material}

At the time of this analysis, Map3D only allowed assigning datum as a single point into space. Although vertical stress could be corrected by introducing topography, horizontal stress was not dissipated by the topography.

The above mentioned issue is minor when topographies are flat, but at El Teniente the topography is abrupt (as shown in Figure 12). Hence, using a single datum value as representative of the whole mine will lead to over or under estimate stress conditions at different locations of the mine.

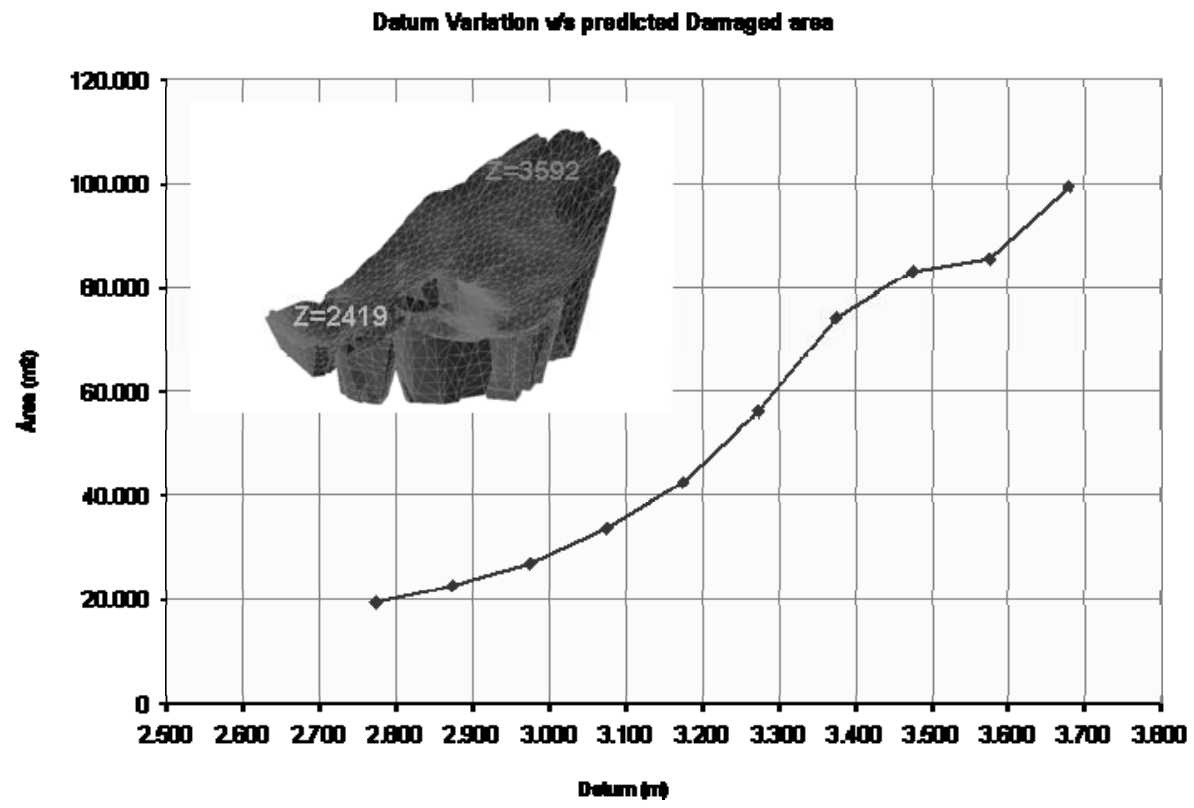

Figure 12 Variation of predicted damaged area due to assumption of cave datum

\subsubsection{Comparison between modelling with and without drives}

Modelling without drives to develop a local criterion can be useful to test assumptions such as pre-mining stress orientation, or to detect changes in rock mass strength from place to place. Nevertheless, back-analysis without drives for damage mapping will not be transferable to locations where the drives are of a different shape or layout. Additionally, as the stress condition around the drives in the undercut level is not properly reproduced, when matching damage $\mathrm{v} / \mathrm{s}$ model predictions the best-fit will underestimate the real strength of the rock mass.

In Figure 13, the same model was run with and without drives, and then criteria to match damage mapping were produced. As can be seen, when comparing both criteria with the stress path for model with drives, the criterion from model without drives will predict damage at points where drives were undamaged.

\subsubsection{Extraction zone stress assumptions}

The loading conditions assumed at the 'extraction zone' will have a large effect on stress redistribution in the area near the undercut front, where damages occur, but will have minor impact on areas where stress measurements are placed. Hence, the geometries and assumptions used in these areas will have a large impact in the model damage prediction. In order to understand the impact on 'extraction nose' an assumption trial model was built. The model considers two assumptions for the cave back. At first, it was assumed that 
the horizontal stresses acting on its wall are the same as the cave wall. Then, cave back was simulated assuming a 'void'; which is an extreme condition.

As can be seen in Figure 14, the impact of nose assumption on stresses at location where stresses were measured had a minor impact. On the other hand, the damaged area prediction is increased as much as 2.5 times, as is shown in Figure 15. In this figure, snapshot on the left shows the damaged area predicted assuming a horizontal stress on the 'extraction zone' equivalent to the stress acting at the same depth on the cave material wall.

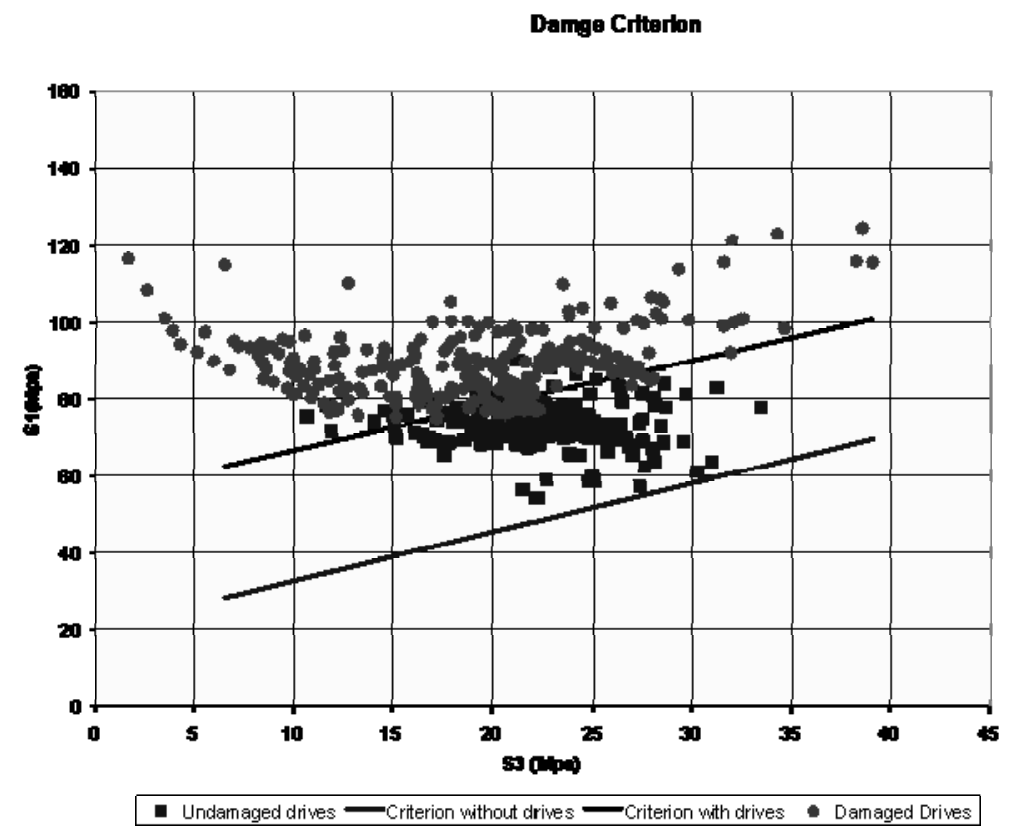

Figure 13 Damage local criterions, with and without drives

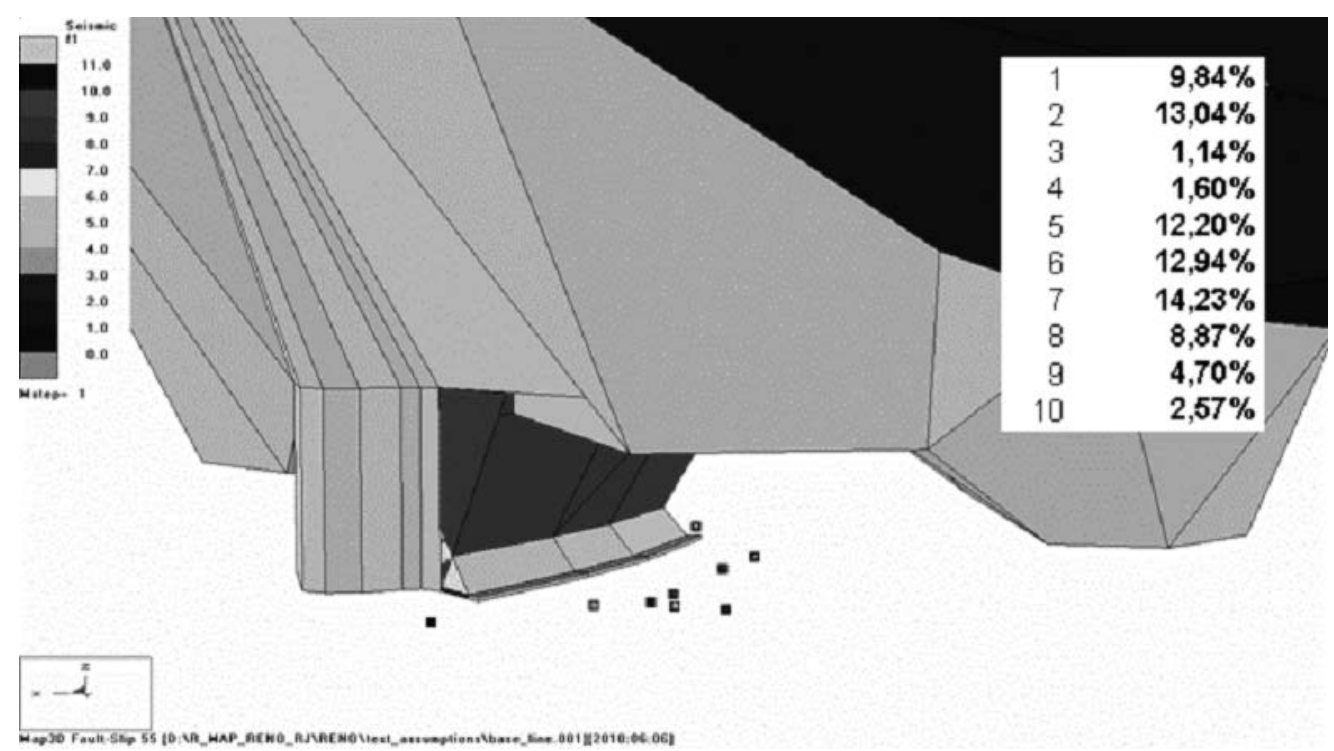

Figure 14 Stress tensor variations and locations of stress measurements 

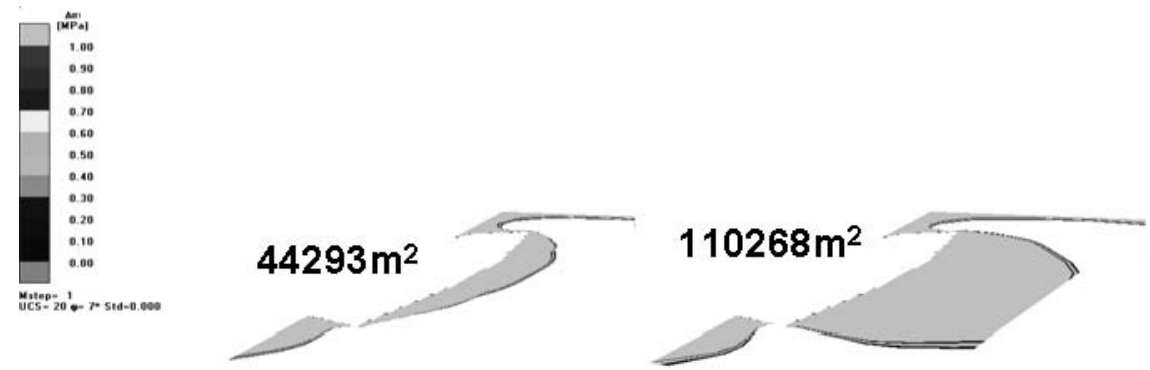

Figure 15 Damage area predictions

\subsection{Definition of damage criterion}

Once all model settings were properly assigned, a consistent criterion was found by selecting the minor and major principal stresses at the boundaries where severe damage was recorded at Reservas Norte sector during year 2005, 2008 and 2009. The derived criterion that best matches the mapped damage at Reservas Norte (see Figure 16), can be written as the following equation:

$$
\sigma_{1}=1.17 * \sigma_{3}+54
$$

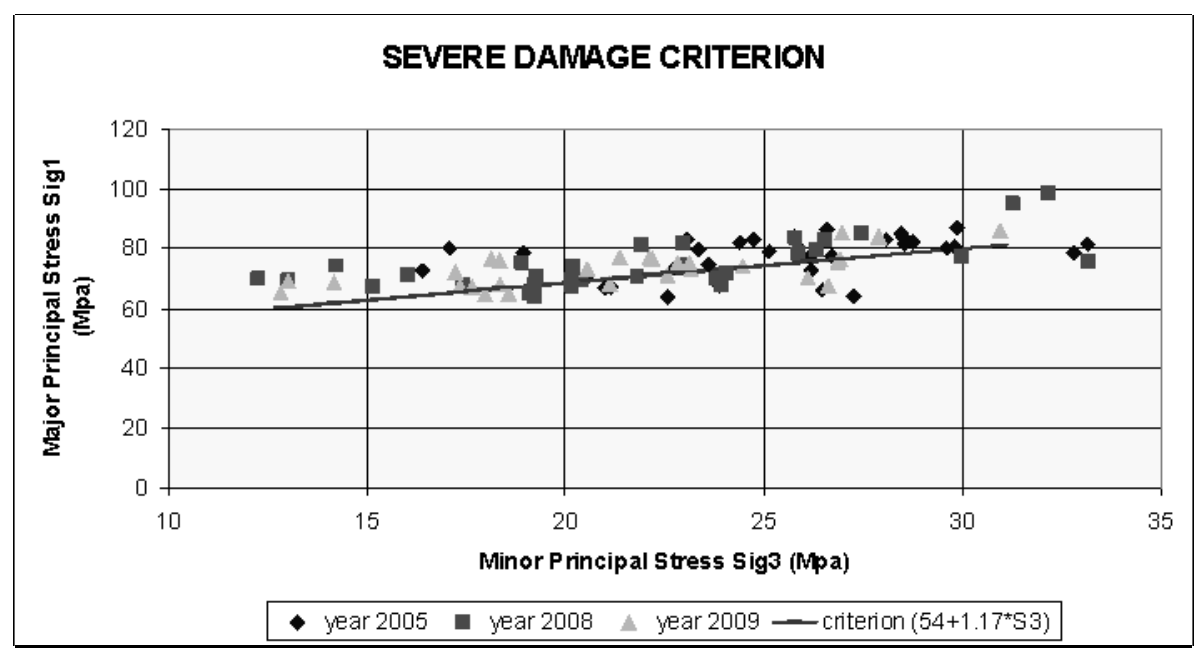

Figure 16 Severe local damage criterion obtained from back analysis, Reservas Norte sector

Applying the local damage criterion, it is possible to identify that results show a satisfactory match, as is shown in Figure 17.
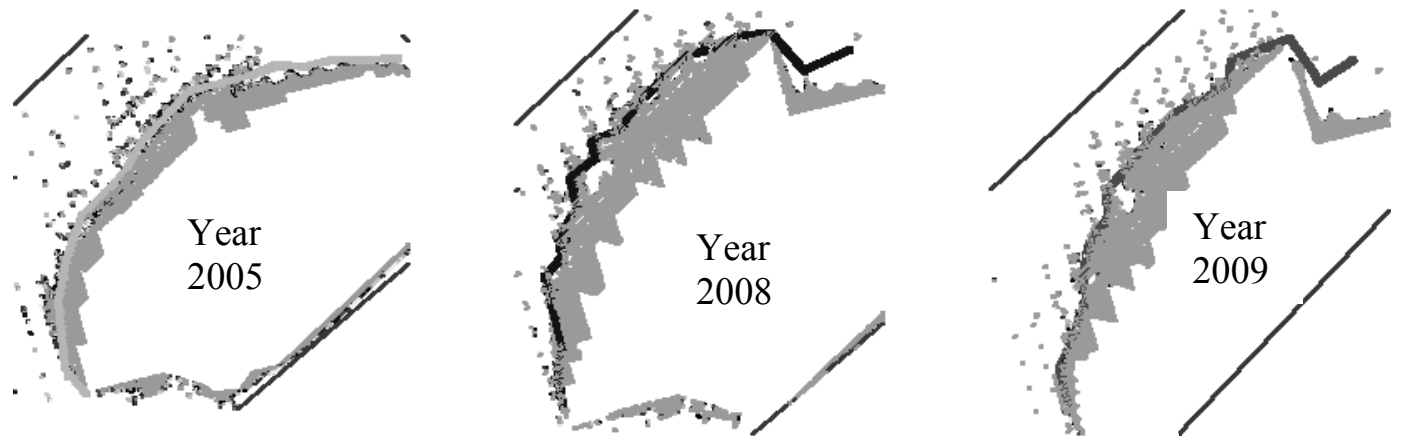

Figure 17 Predicted versus mapped damage at the undercut level 


\subsection{Limitations of the analysis}

There is evidence that time under load can deteriorate the rock mass conditions. This phenomenon will take place in areas that remain long periods under loading originated by the undercut and cave. This effect cannot be incorporated in the models presented in this study.

\section{Conclusions}

Severe rock mass damage at the Reservas Norte undercut level can be predicted by applying a single criterion base on the major and minor principal stresses. The results of a three period analysis of the mine have shown a consistent correlation between mapped and model damage prediction.

As discussed in this paper, the use of an elastic modelling can be a powerful tool to estimate areas at the undercut level which may experience severe damage. Nevertheless, the assumption made in the model can have a large impact in the results and predictions. Therefore, before applying this methodology to predict rock mass damage the user must be aware of the impact of such assumptions in the model response.

\section{Acknowledgements}

The authors wish to thank Codelco Chile División El Teniente for allowing the publication of this work. We also want to thank Dr Terry Wiles for his valuable contributions to the numerical modelling work at El Teniente Mine.

\section{References}

Benado, D. (2009) Actualización de planos geológicos Nivel de Hundimiento Mina Reservas Norte, Internal report, Superintendencia de Geología, Codelco Chile División el Teniente, Chile.

Brzovic, A. (2000) Geología y Geotecnia Quinquenio Mina Teniente Sub-6 Proyecto Reservas Norte, Internal Report, Superintendencia de Geología, Codelco Chile División el Teniente, Chile.

Cuello, D., Jiménez, R. and Cavieres, P. (2010) Modelo Numérico Lado Norte Mina el Teniente, Internal Report, Superintendencia de Geomecánica, Codelco Chile División el Teniente, Chile.

Pardo, C. and Landeros, P. (2008) Numerical modeling at El Teniente Mine, internal report TTAB 2008, Superintendencia de Geomecánica, Codelco Chile División el Teniente, Chile.

Rojas, E., Molina, R. and Cavieres, P. (2001) Pre-undercut caving in El Teniente Mine Chile, Underground mining methods: engineering fundamentals and international case studies, SME, pp. 417-423.

Wiles, T. (1999) MAP3D Course Notes. 